1 O'Hara MW. The nature of postpartum depressive disorders. In: Murray L, Cooper PJ, eds. Postpartum depression and child development. New York:

2 Cooper PJ, Campbell EA, Day A, Kennerley H, Bond A. Non-psychotic psychiatric disorder after childbirth: a prospective study of prevalence, incidence, course and nature. Br F Psychiatry 1988;152:799-806.

3 O'Hara MW, Zekoski EM, Phillips LH, Wright EJ. A controlled prospective study of postpartum mood disorders: comparison of childbearing and nonchildbearing women. $\mathcal{F}$ Abnorm Psychol 1990;99:3-15.

4 Troutman BR, Cutrona CE. Nonpsychotic postpartum depression among adolescent mothers. F Abnorm Psychol 1990;99:69-78.

5 Cox JL, Murray D, Chapman G. A controlled study of the onset, duration and prevalence of postnatal depression. Br F Psychiatry 1993;163:27-31.

6 Cooper PJ, Murray L, Stein A. Postnatal depression. In: Seva J, ed. The European handbook of psychiatry and mental health. Zaragos: Anthropos, 1991: 1255-62.

7 Seeley S, Murray L, Cooper PJ. The outcome for mothers and babies of health visitor intervention. Health Visitor 1996;69:135-8.

8 Murray L, Cooper PJ. Effects of postnatal depression on infant Murray L, Cooper PJ. Effects of postnat
development. Arch Dis Child 1997;77:99-101.

9 Murray L, Cartwright W. The role of obstetric factors in postpartum Murray L, Cartwright W. The role of obstet

10 O'Hara, MW, Schlechte JA, Lewis DA, Varner MW. A controlled prospective study of postpartum mood disorders: psychological, environmental, and hormonal variables. F Abnorm Psychol 1991;100:63-73.

11 Kendell RE. Emotional and physical factors in the genesis of puerperal mental disorders. F Psychosom Res 1985;29:3-11.

2 Appleby L, Gregoire A, Platz C, Martin P, Kumar R. Screening women for high risk of postnatal depression. $\mathcal{F}$ Psychosom Res 1994;38:539-45.

13 Cooper PJ, Murray L. The course and recurrence of postnatal depression. Br F Psychiatry 1995;166:191-5.
14 Cooper PJ, Murray L, Hooper R, West A. The development and validation of a predictive index for postpartum depression. Psychol Med 1996;26:627-34.

15 Murray L, Stanley C, Hooper R, King F, Fiori-Cowley A. The role of infant factors in postnatal depression and mother-infant interactions. Dev Med Child Neurol 1996;38:109-19.

16 Brazelton TB. Neonatal behavioural assessment scale. 3rd Ed. Clinics in Developmental Medicine No 137. London: McKeith Press, 1995.

17 Kennerley H, Gath D. 'Maternity blues': detection and measurement by questionnaire. Br F Psychiatry 1989;155:356-73.

18 Briscoe ME, Williams P. Emotional problems in the clients of health visitors. Health Visitor 1985;58:197-8.

19 Cox JL, Holden JM, Sagovsky R. Detection of postnatal depression: development of the 10-item Edinburgh postnatal depression scale. Br f Psychiatry 1987;150:782-6.

20 Murray L, Carothers AD. The validation of the Edinburgh postnatal depression scale on a community sample. Brf Psychiatry 1990;157:288-90.

21 Gregoire AJP, Kumar R, Everitt B, Henderson AF, Studd JWW. Transdermal oestrogen for treatment of severe postnatal depression. Lancet 1996;347:930-3.

22 Appleby L, Warner R, Whitton A, Faragher B. A controlled study of fluoxetine and cognitive-behavioural counselling in the treatment of postnatal depression. BM7 1997;314:932-6.

23 Holden JM, Sagovsky R, Cox JL. Counselling in a general practice setting: controlled study of health visitor intervention in treatment of postnatal depression. BM7 1989;298:223-6.

24 Cooper PJ, Murray L. The impact of psychological treatments of postpartum depression on maternal mood and infant development. In: Murray L, Cooper PJ, eds. Postpartum depression and child development. New York: Guilford, 1997: 201-20.

\title{
Effects of postnatal depression on infant development
}

There is good evidence that parental psychiatric disorder has a deleterious effect on child development. Rutter has outlined a number of possible reasons for this. ${ }^{1}$ First, there may be a direct pernicious impact on the child of exposure to the parental disorder. Second, there may be an indirect impact via the effect of the parental disorder on interpersonal behaviour in general and parenting in particular. Finally, the impact may be via third factor variables, such as the social adversity commonly associated with psychiatric disorder, or genetic or constitutional factors. Depression arising in the postnatal period could have an impact on infant development via each of these causal pathways. The infant's extreme dependency on their caretaker, their sensitivity to interpersonal contacts, ${ }^{2}$ and the fact that, in the great majority of cases, the mother constitutes the infant's primary environment in the first postnatal months, make the question of the impact of depression occurring at this time one of particular importance. An account is given below of the evidence implicating postnatal depression in adverse infant outcome. This evidence is then examined in the light of the possible causal frameworks outlined above.

A number of studies have examined the 1 to 2 year old infants of mothers who have had a postnatal depression..$^{3-8}$ These studies have generally found an association between early maternal depression and adverse cognitive and emotional infant development.

\section{Cognitive development}

Two studies have reported on the cognitive outcome of 12 to 18 month old infants of mothers who had had a postnatal depression. Lyons-Ruth et al, in a comparison of American mothers and infants who had been referred to an infant intervention service with matched community controls, ${ }^{3}$ found that increased levels of maternal depression were significantly related at 1 year to poorer infant mental and motor development as assessed by the Bayley scales. ${ }^{9}$ This association was still present when maternal IQ had been controlled. Similarly, Murray, in a comparison of the development of a British community sample of full term healthy infants of primiparous women who had either remained well or who had been depressed postnatally, found a significant difference between the two groups of infants in terms of a number of indices of cognitive development. ${ }^{5}$ Thus, at an 18 month follow up, compared with the infants of postnatally well mothers, infants of mothers who had had postnatal depression were significantly more likely to fail on stage V of Piaget's object permanence task, a key measure of the infant's capacity for mental representation; and on the Bayley scales of mental development, an interaction was found between maternal mental state and infant gender: the boys of mothers who had had postpartum depression performed particularly poorly.

\section{Emotional development}

The impact of postnatal depression on the emotional development of infants has been studied in three ways.

(1) An examination has been made of the quality of the infant's interpersonal functioning when in direct communicative engagement with the mother. Stein and colleagues made standardised ratings of the quality of mother-infant interactions in free and structured play in the home in a community sample of mothers who had had a postnatal depression and their 19 months old infants, together with well controls. ${ }^{4}$ Compared with the latter group, the children of the index mothers showed less affective sharing, a lower rate of overall interactive behaviour, less concentration, and more negative responses. These infants also showed less sociability to a stranger.

(2) Assessments have been made of the quality of infant attachment (assessed by means of the Ainsworth strange situation procedure ${ }^{10}$ ). Four longitudinal studies have been carried out on postpartum samples where systematic assessment of infant attachment has been made. LyonsRuth and colleagues found an association between insecure attachment at 12 months and high levels of maternal depression. ${ }^{3}$ Similarly, Murray found a significant association between the occurrence of depression in the postnatal period and insecurity of attachment at 18 months postpartum, with avoidance being the prominent insecure attachment profile. ${ }^{5}$ This association between the postnatal 
mood disorder and insecure infant attachment to the mother was also found in a study conducted by Teti and colleagues in which clinically referred mothers with depression and their infants were compared with a non-depressed control group. ${ }^{7}$ In contrast to these three reports, Campbell and Cohn, in a low risk community sample, found no association between attachment status and maternal depression. ${ }^{8}$ However, some caution is required when considering this last result as the rate of follow up was low, and high rates of insecurity were present in both case and control groups. Finally, although Stein and colleagues made no formal assessment of attachment, they did make observations of the infant's reaction to being separated from the mother when in the presence of a stranger: distress was evidenced by significantly fewer of the children of the mothers who had had a postnatal depression, possibly indicative of a higher rate of avoidant attachments. ${ }^{4}$

(3) Finally, account has been taken of the level of behavioural problems. Murray interviewed mothers when their children were 18 months of age using a modified version of the behavioural screening questionnaire ${ }^{11}$ and found that, compared with women who had been well in the postnatal period, those who had experienced postnatal depression were more likely to report behavioural difficulties in the child. ${ }^{5}$ These principally concerned sleeping and eating problems, temper tantrums, and separation difficulties.

Taken together these studies attest to a significantly raised level of emotional disturbance in late infancy in the children of mothers who have had a postnatal depression.

\section{Mediating mechanisms}

As noted above, a number of mechanisms may mediate the association between the occurrence of postnatal depression and adverse infant outcome.

(1) The most direct environmental route to be considered is the child's exposure to the mother's depressive symptoms. It is certainly the case that, in the study of Lyons-Ruth and colleagues, infant outcome in terms of both cognitive development and attachment security was more compromised in the context of severe, rather than mild, maternal depression. ${ }^{3}$ In addition, Campbell et al found poor infant behaviour to occur in the context of interactions with the mother where the mother was chronically, but not more briefly, depressed. ${ }^{12}$ In contrast, other studies have found adverse infant outcome to obtain in spite of maternal remission from depression some months before the infant assessment. Thus, Stein et al found poor infant behaviour at 19 months to obtain in cases where the mother had been depressed postnatally, whether or not she had recovered by the time of the infant assessment. ${ }^{4}$ Similarly, Murray found the insecure attachment, behaviour problems, and poorer cognitive outcome associated with the occurrence of postnatal depression to obtain in infants of 18 months even though, in the great majority of cases, the mother's depression had remitted by around six to eight months postpartum. ${ }^{5}$ In this study, moreover, there was no association between infant outcome and the severity of the mother's postpartum depressive episode. These latter findings indicate, therefore, that although the infant's exposure to severe and prolonged depressive symptoms may contribute to poor outcome, other aspects of the infant's environment may also be important.

(2) The second causal route is via parenting difficulties associated with the occurrence of maternal depression. It is well established that depression is associated with a range of persistent difficulties in interpersonal functioning. Weissman and Paykel described, for example, how women who had experienced depression, but remitted, continued to show raised levels of irritability or withdrawn behaviour in the context of their close family relationships. ${ }^{13}$ It may be the case, therefore, that the experience of postpartum depression sets in train a pattern of relating to the infant that remains compromised in the longer term, in spite of the relatively brief duration of the initial episode. Support for this hypothesis comes from the study of Stein et al, who found the quality of maternal interactions with the infant to differ between well control group mothers and index mothers who had recovered from depression by the time of the assessment. ${ }^{4}$

In the study of Murray and colleagues, assessments were made of the quality of the maternal interactions with the infant at two months postpartum. As expected, the responsiveness of the depressed mothers was generally poorer than that of the well controls; and when the nature of this early maternal interactive behaviour was considered, it was found to account for the differences in the cognitive outcome at 9 and 18 months of the depressed and well mothers' infants. ${ }^{6}{ }^{14}$ The interactive style associated with the occurrence of depression, therefore, rather than exposure to depressive symptoms per se, carries the major explanatory force. This conclusion is supported by studies of mother-infant interactions conducted in the US. Cohn and colleagues, for example, found that, within a postpartum depressed group, the form of the infant's response was systematically related to the particular quality of maternal behaviour: those with disengaged mothers showed high rates of protest behaviour, while those whose mothers were intrusive were avoidant. ${ }^{15}$ Such specificity in the associations between maternal and infant behaviours has been confirmed by Field et al. ${ }^{16}$ Finally, the study of Teti and Gelfand showed that maternal cognitions associated with depression were more important in explaining the quality of the mother-infant relationship than the occurrence of depression itself. ${ }^{17}$ Together these studies indicate that the primary determinant of the infant behaviour and outcome is the particular form of maternal responsiveness rather than the presence of depression per se.

(3) The third possible causal route is via third factor variables:

(A) Environmental adversity: as noted by Cooper and Murray, postnatal depression often occurs in the context of social and personal adversity. ${ }^{18}$ Since there is good evidence that such factors in themselves are associated with poor child outcome,${ }^{19}$ it is possible that any association between postpartum depression and adverse infant development arises as a function of factors such as overcrowding, poverty, or marital discord, independent of the maternal mood disorder. Comparison of populations of depressed mothers in very differing social circumstances lends support to the idea that social adversity may well be of significance in understanding the adverse outcome of the offspring of postnatally depressed women. Thus, a number of studies conducted with very disadvantaged groups by Field and Cohn and colleagues have found depressed mothers' interactions with their infants to evidence high rates of marked disturbance. ${ }^{15162021}$ In contrast, those conducted with low risk samples found the interaction difficulties of depressed mothers to be less extreme. ${ }^{6121422}$ The impact of adversity has also been discernible within samples. Thus, Teti and colleagues found that, within a sample of postnatally depressed women, deficits in maternal feeding and play with the infant were significantly related to the presence of adversity. ${ }^{23}$ Similarly, Murray et al found that non-depressed women experiencing significant adversity showed similar interaction deficits to depressed women ${ }^{6}$; nevertheless, it remained the case that depressed women experiencing no adversity still showed significant interaction deficits compared with controls. In sum, while it is certainly the case that adversity is associated with more 
adverse mother-child relationships, and that adversity tends to stack up in depressed samples, the occurrence of depression itself is pernicious.

(B) Genetic/constitutional factors: while it has generally been assumed that associations between maternal depression and poor child outcome arise because of the impact of maternal factors on the child, recent research has highlighted the fact that relations between parents and their children are bidirectional in their influence. ${ }^{24}$ The possibility therefore needs to be addressed that poor child outcome, parenting difficulties, and even maternal depression itself may all be influenced by infant factors.

This question is difficult to address since it requires prospective investigation of the infant, independent of maternal functioning. However, Cutrona and Troutman found that the presence of irritable behaviour in the infant contributed to the persistence of depression. ${ }^{25}$ Similarly, Murray and colleagues found that certain infant characteristics (irritability and poor motor control), measured before the onset of any maternal depression at 10 days postpartum, significantly increased the risk that the mother would become depressed. ${ }^{26}$ Nevertheless, there was no evidence from the study of Murray and colleagues that infant factors had an independent impact on the quality of the mother-infant relationship at two months, and nor was there evidence for an impact of early infant characteristics on the longer term cognitive and emotional outcome of the child. Both the quality of maternal responsiveness and child outcome were, as noted above, principally affected by the presence of depression and social adversity.

\section{Conclusion}

It is evident that postnatal depression poses a risk for the mother-infant relationship and infant developmental outcome. The adverse effects of postnatal depression appear to be mediated through its association with maternal cognitions and parenting. The impact is likely to be more pernicious where the depressive episode is severe and prolonged, and where it occurs in the context of personal and social adversity.

LYNNE MURRAY

Department of Psychology,

The University of Reading,

Whiteknights, Reading RG6 $6 \mathrm{AL}$

1 Rutter M. Psychiatric disorder in parents as a risk factor for children. In: Schaffer D, Philips I, NB Enger NB, eds. Prevention of mental disorder, alcohol and other drug use in children and adolescents. Rockville, Maryland: Office for Substance Abuse, USDHHS, 1989.

2 Murray L. Effects of postnatal depression on infant development: direct studies of early mother-infant interactions. In: Kumar R, Brockington I, eds. Motherhood and mental illness. Vol 2: causes and consequences. London: Butterworths, 1988:159-90.

3 Lyons-Ruth K, Zoll D, Connell D, Grunebaum HU. The depressed mother and her one-year-old infant: environment, interaction, attachment and infant development. In: Tronick EZ, Field T, eds. Maternal depression and infant disturbance. New directions for child development. San Francisco: JosseyBass, 1986: 34

4 Stein A, Gath DH, Bucher J, Bond A, Day A, Cooper PJ. The relationship between postnatal depression and mother-child interaction. Br f Psychiatry 1991;158:46-52.

5 Murray L. The impact of postnatal depression on infant development. $\mathcal{F}$ Child Psychol Psychiatry 1992;33:543-61.

6 Murray L, Fiori-Cowley A, Hooper R, Cooper PJ. The impact of postnatal depression and associated adversity on early mother infant interactions and later infant outcome. Child Dev 1996;67:2512-26.

7 Teti DM, Gelfand CM, Messinger DS, Isabella R. Maternal depression and the quality of early attachment: an examination of infants, preschoolers, and their mothers. Developmental Psychology 1995;31:364-76.

8 Campbell SB, Cohn JF. The timing and chronicity of postpartum depression: implications in infant development. In: Murray L, Cooper PJ, eds. Postpartum depression and child development. New York: Guilford Press, 1997: 165-97.

9 Bayley N. The Bayley scales on infant development. New York: The Pschological Corporation, 1969.

10 Ainsworth MD, Wittig BA. Attachment and exploratory behaviour in one-year-olds in a strange situation. In: Floss BM, ed. Determinants of infant behaviour. London: Methuen, 1969:4.

11 Richman N, Graham P. A behavioural screening questionnaire for use with three-year old children: preliminary findings. F Child Psychol Psychiatry 1971;12:5-33

12 Campbell SB, Cohn JF, Meyers T. Depression in first-time mothers: mother-infant interaction and depression chronicity. Developmental Psychology 1995;31:349-57.

13 Weissman MM, Paykel ES. The depressed woman: a study of social relationships. Chicago: University of Chicago Press, 1974.

14 Murray L, Kempton C, Woolgar M, Hooper R. Depressed mothers' speech to their infants and its relation to infant gender and cognitive development. f Child Psychol Psychiatry 1993;34:1083-101.

15 Cohn JF, Matias R, Tronick EZ, Connell D, Lyons-Ruth D. Face-to face interactions of depressed mothers and their infants. In: Tronick EZ, Field $\mathrm{T}$, eds. Maternal depression and infant disturbance. New directions for child development. San Francisco: Jossey-Bass, 1986:34.

16 Field T, Healy B, Goldstein S, Guthertz M. Behavior-state matching and synchrony in mother-infant interactions in nondepressed versus depressed dyads. Developmental Psychology 1990;26:7-14.

17 Teti DM, Gelfand DM. Behavioral competence among mothers of infants in the first year: the mediational role of maternal self-efficacy. Child Dev 1991; 62:918-29.

18 Cooper PJ, Murray L. Prediction, detection, and treatment of postnatal depression. Arch Dis Child 1997;77:97-9.

19 Rutter M, Quinton D. Parental psychiatric disorder: effects on children. Psychol Med 1984;14:853-80.

20 Field TM, Sandberg D, Garcia R, Vega-Lahr N, Goldstein S, Guy L. Pregnancy problems, postpartum depression and early mother-infant interactions. Dev Psychol 1985;21:1152-6.

21 Field T, Healy B, Goldstein S, et al. Infants of depressed mothers show 'depressed' behaviour even with nondepressed adults. Child Dev 1988; 59: 1569-1579.

22 Cohn JF, Campbell SB, Matias R, Hopkins J. Face-to-face interaction of postpartum depressed and nondepressed mother-infant pairs at 2 months. Developmental Psychology 1990;26:15-23.

23 Teti DM, Gelfand DM, Pompa J. Depressed mothers' behavioral competence with their infants: demographic and psychosocial correlates. competence with their infants: demographic and
Developmental and Psychopathology 1990;2:259-70.

24 Sameroff AJ. The social context of development. In: Woodhead M, Carr R, Light P, eds. Child development in social context: becoming a person. Open University Reader E820. London: Routledge, 1991.

25 Cutrona CE, Troutman BR. 'Social support, infant temperament, and parenting self-efficacy: a mediational model of postpartum depression. Child Dev 1986;57:1507-18.

26 Murray L, Stanley C, Hooper R, King F, Fiori-Cowley A. The role of infant factors in postnatal depression and mother-infant interactions. Dev Med Child Neurol 1996;38:109-19. 